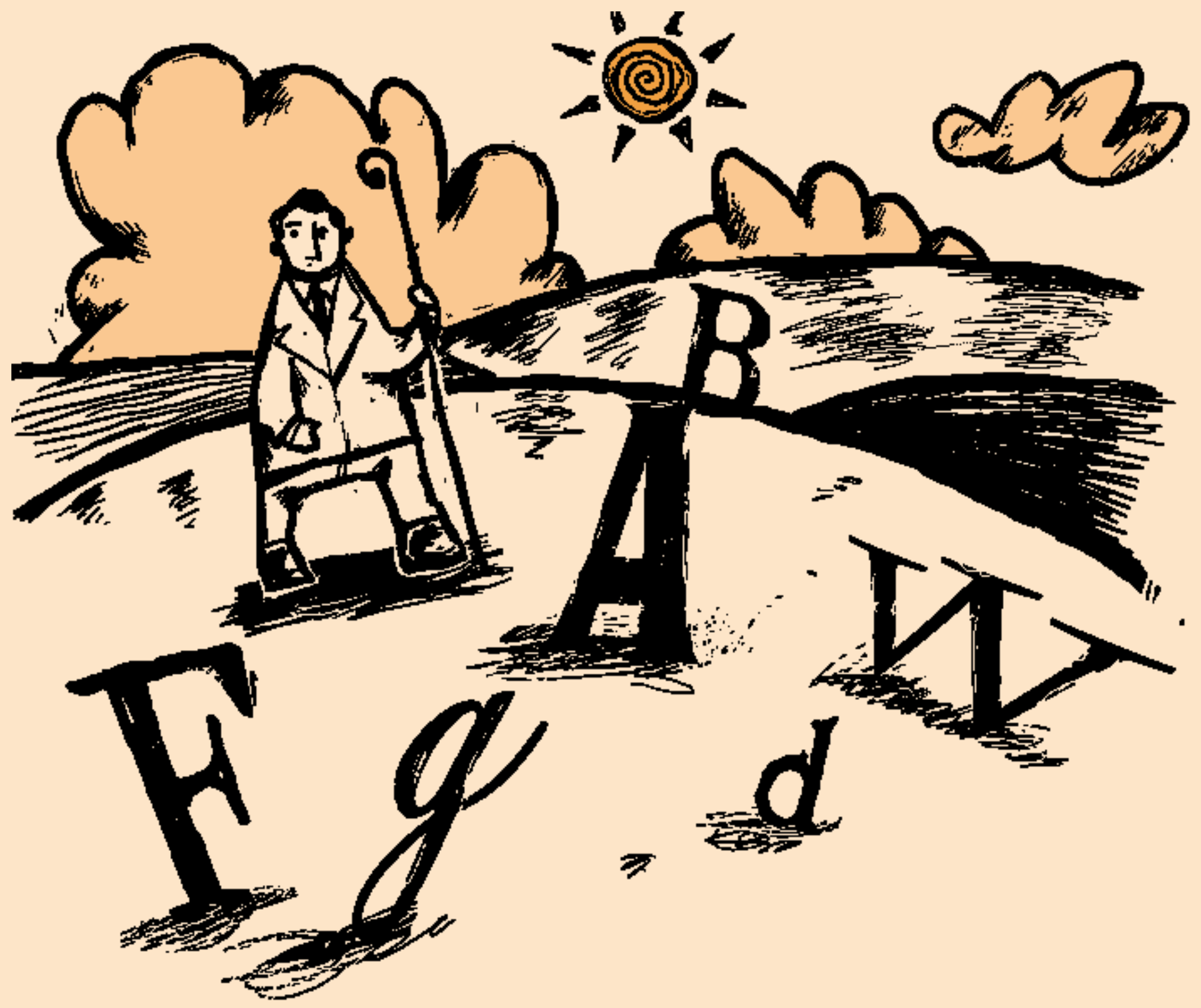




\section{Comunicación: profesión de la cultura}

Mariluz Restrepo

- Comunicadora social y magíster en Filosofia de la Pontifícia Universidad J averiana de Bogotá

- Estudios de Doctorado en Filosofía

- Directora de Humanidades e Idiomas de la Escuela Colombiana de Ingeniería "J ulio Garavito"

- Profesora de la Universidad Nacional de Colombia

- Ha sido consultora en Comunicación para la UNICEF y directora de Comunicación en la IBM 


\section{Resumo}

A autora faz uma reflexão sobre o papel dos comunicadores tendo como ótica sua relação com a cultura em um ambiente pós-moderno de novos meios, de criação e recriação de símbolos e atitudes. Uma nova dimensão abre-se ao comunicador, permitindo gerar outros processos de comunicação, deslocando os processos meramente informacionaise efetivistas para fazer justiçaà comunicação humana, confrontando versões, apresentando novosmundose possibilidades, mostrando e construindo, sobretudo, cultura.

PALAVRAS-CHAVE: COMUNICAÇÃo - CULTURA - Pós-MOdeRnidade • NOVOS MEIOS - PROCESSOS DE COMUNICAÇÃO

\section{Abstract}

The author reflects on the role of communication professionals, focusing their relationship with the culture in a postmodern environment, one of new media and of creation and re-creation of symbols and postures. A new dimension is revealed to thisprofessional, permitting the rise of other communicational processes, displacing those which are merely informational and instrumental in order to reinforce human communication, confronting versions, presenting new worlds and possibilities, showing and building culture above all.

KEY WORDS: COMMUNICATION - CULTURE - POST MODERNITY - NEW MEDIA - COMMUNICATIONAL PROCESSES

\section{Resumen}

La autora reflexiona sobre el papel de los especialistas en comunicación partiendo de su relación con la cultura en el entorno postmoderno de losnuevos mediosy de creación y re-creación de símbolos y actitudes. El especialista se depara con una nueva dimensión, que le permite generar otros procesos de comunicación desplazando los procesos meramente informativos e instrumentales para centrarse en la comunicación humana confrontando versiones, presentando nuevos mundos y posibilidades y, principalmente, mostrando y construyendo cultura.

Palabras Clave: COMUNicación - CUltura - POSTMOdernidad - NUevos medios • PROCESOS DE COMUNICACIÓN 
V olver sobre el tema comunicación-cultura parecerá a ojos de muchos como trasnochado. Que la comunicación es un fenómeno inserto en la cultura ya nadie lo pone en duda. Pero que esta intrínseca relación haya permeado el trabajo de quienes de una u otra forma ejercen funciones de comunicación aún no parece estar tan asumido. Q uiero volver hoy sobre esta relación, décadas después del debate que la colocó como un hecho dado, para confrontarla con el ejercicio de profesar la comunicación. M e dirijo particularmente a quienes han escogido trabajar como comunicadores utilizando la palabra, los gráficos y otras imágenes, el cuerpo, los sonidos y las mezclas entre ellos, es decir, a quienes hacen de estas manifestaciones su vida al servicio de otros para llevar a grupos humanos posibilidades de sentido.

\section{Cultura: naturaleza humana}

Empiezo por poner en tela de juicio aquellos conceptos reducidos de cultura que la limitan a modos particulares del pensar y del hacer humanos, generalmente referidos a conocimientos 'sofisticados' 0 a formas de proceder propias de las diversas artes a veces también folcorizándolas. Si bien se asumen superados en teoría estos conceptos, no parecen estarlo cuando se sigue hablando de 'actividades culturales' para referirse solamente a ciertas expresiones humanas, o cuando entidades dedicadas a gestionar y promover procesos culturales los escinden de los modos de vivir cotidianos.

Entiendo con Ladrière (1977) cultura - en el más amplio sentido del término - como lo que da a la vida de una colectividad histórica su configuración específica. Es la expresión de un punto de vista original e irreductible sobre el mundo y sobre el significado del ser humano. Implica una perspectiva particular, un modo de entender y de gozar el mundo. La cultura le ofrece a cada ser humano un sistema de interpretación del mundo, diríamos una 'forma de vida' por y en la que se configura su existencia y en cuyo contexto se va construyendo su destino particular como individuo y como comunidad. La culturajuega un doble papel: nos proporciona un arraigo, es decir, nos sitúa en un tiempo y en un mundo determinado y a la vez nos coloca en apertura, en un cierto horizonte de posibilidades. En consecuencia, permite que cada quien se encuentre en el mundo y se interprete a sí mismo como ser humano dando sentido a lo que emprende. Y, simultáneamente, precisamente porque los seres humanos son capaces de ser emprendedores, se van configurando las culturas. En otras palabras, la cultura se refiere a todo aquello que hace que tanto individuos como sociedades sean lo que van siendo. 
Tal concepción tan amplia imposibilita una definición ya que cualquiera la reduciría traicionándola. Prefiero continuar con Ladrière (1977, p.14-15) y retomar el modo en que, desde una perspectiva sistémica, él la describe:

"La cultura de una colectividad es el conjunto formado por los sistemas de representación, los sistemas normativos, los sistemas de expresión deesa col ectividad. Los sistemas de representación abarcan los conjuntos conceptuales y simbólicos a través de los cuales los diferentes grupos que constituyen la colectividad tratan de interpretarse a sí mismos y al mundo en que están inmersos y, también, los métodos por los cuales trata dicha colectividad deampliar sus conocimientos y su savoir-faire. Los sistemasnormativos agrupan todo lo que depende de los valores con los que se juzgan las acciones y las situaciones $y$, a partir de los cuales, eventualmente, sejustifican, las prácticas concretas y, por otra parte, todo lo que depende de reglas particulares por medio de las cuales se organizan los sistemas de acción.

Los sistemas de expresión contienen las modalidades, a la vez materiales y formales, por las quelas representaciones y las normas consiguen su proyección concreta, en el ámbito dela sensibilidad y gracias a las cuales los estados profundos (en los que se materializa la existencia vivida, como modo de experimentar la realidad natural e histórica) se exteriorizan como figuras significantes, ofrecidas a un desciframiento constante. Estos sistemas de acción, comprenden, a su vez, las mediaciones técnicas que permiten dominar - más o menos adecuadamente - el medio social y las mediaciones propiamente sociales, a través de las cuales seorganiza la colectividad para seguir su propio destino."

En esta descripción de la cultura el énfasis evidentemente se sitúa en el sistema de expresión que se refiere a todas las modalidades de la acción humana incluyendo sus productos, a través de los cuales se revelan las formas en que cada colectividad histórica se representa y valora a sí misma en el mundo, y estas formas están abiertas "a un desciframiento constante". Esto quiere decir que están sujetas a múltiples interpretaciones que se van reflejando en nuevas acciones humanas. Toda interpretación es fuente de luz existencial; funciona como apertura de una posibilidad indefinida de reinter pretaciones. De ahí que una inter pretación jamás sea totalmente clara para sí misma, es siempre prospectiva. Cuando propone un sentido, indica al mismo tiempo que dicho sentido, ojalá, genere nuevos sentidos, otras inter pretaciones. Estamos situados en una perspectiva dinámica de la cultura que se constituye en la necesidad de una perpetua recreación del sentido. De ahí que sean múltiples las culturas, profundamente diversificadas y que estén en continua transformación. La cultura no es algo ya instituido, sino que es, como bien lo explica Castoriadis (1975), 'instituyente' en tanto hace parte de la tarea nunca acabada de hacernos humanos.

El ser humano es 'pro-yecto' porquees lanzado hacia adelante y por ello mismo es siempre pre-visor: está orientado como Prometeo a lo lejano, ni al presente en el tiempo ni en el espacio. Al contrario del animal, vive para el futuro y no en el presente. Por ser trascendente, el ser humano es un 'acto-de-superación jamás acabado'. Su hori- 
zonte es aquello que está siempre más allá y que jamás al canza aun cuando siempre camine hacia él. "Esta abertura de principio, esta accesibilidad a la 'obra' 0 al proyecto del hombre en cuanto tal es el que funda la persona brindándole su horizonte de humanidad, entendida como totalidad que hay-quehacerse; es lo que representa la condición de posibilidad de la persona" (Ricoeur, 1982, p.153). La existencia humana es siempre una tarea por hacerse.

"La existencia humana se integra en el esfuerzo en quese construyea sí misma por la acción. Cuando actúa el ser humano no se separa del mundo, por el contrario, se entrega a él, lo explora en todas las dimensiones que ofrece, se sumergeen él para encontrar allí su sentido" (Arendt, 1958, p.178). La acción que el ser humano inicia es desplegada por la palabra y, aunque sus actos se perciben en su apariencia física sin el acompañamiento verbal, sólo se vuelven relevantes a través de la palabra dicha en la que se identifica como actor, anunciando lo que hace, lo que ha hecho y lo que intenta hacer. A través de la acción y del decir el hombre revela lo que es y así hace su aparición en el mundo humano.

"La acción humana solo puede abrirse camino entre los condicionamientos en que se muevea condición de permanecer siempre vigilante y de reinterpretar constantemente los términos de que se sirve para dar forma a su sentido y proponerse unos fines. Dicho de otro modo, su destino depende de su creatividad" (Ladrière, 1977, p.192). En esta tarea nunca acabada de

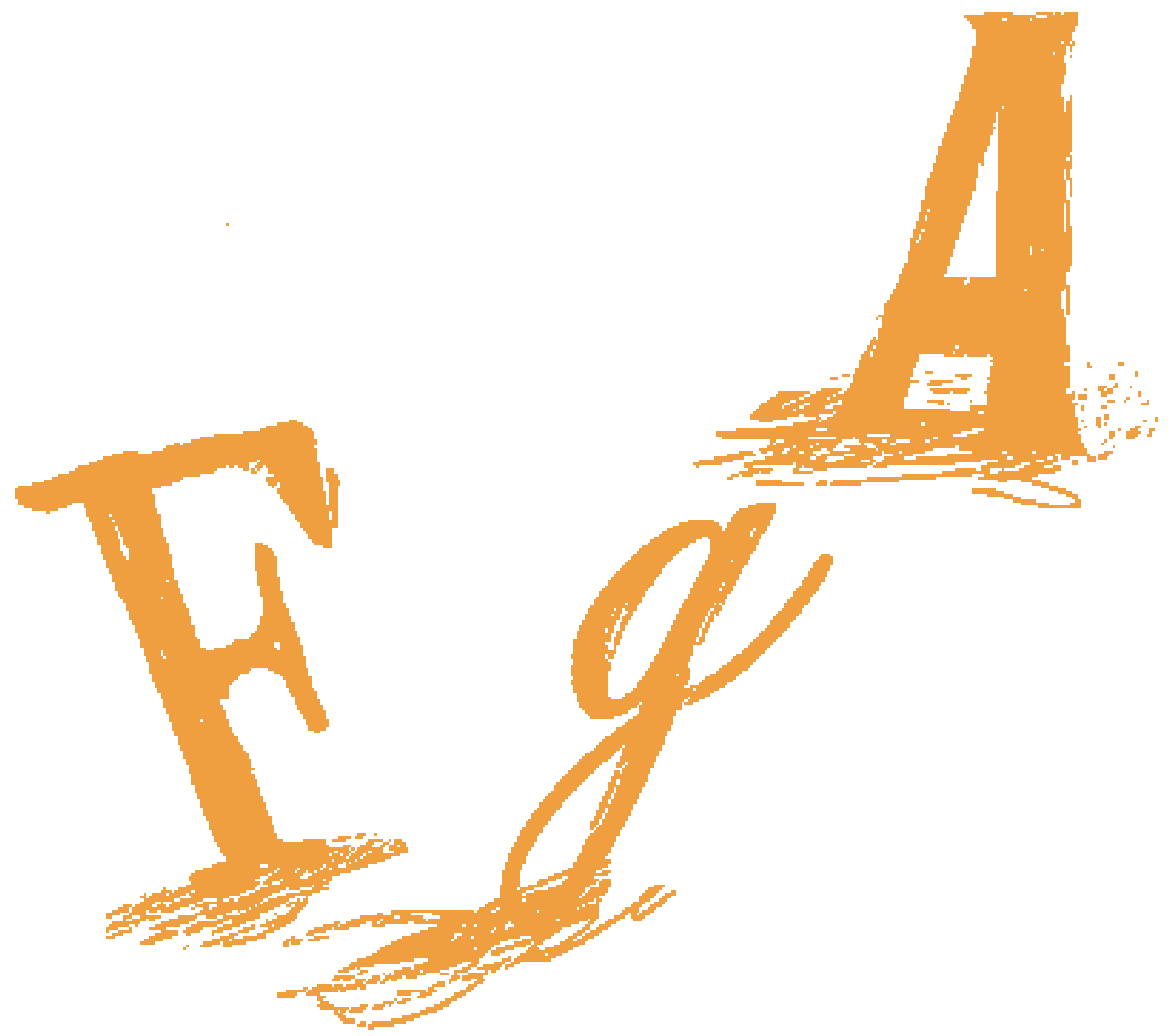


incidir sobre la propia vida se despliega la autonomía humana, autonomía como apertura ontológica que nos posibilita poner en tela de juicio lo que como humanos hemos instituido. Significa poder alterar lo existente apropiando el mundo, creando un nuevo eidos, otro sí-mismo diferente, inaugurando otros mundos posibles. Toda acción implica una toma de posición valorativa sobre lo existente. Se actúa a partir de una situación dada porque nada está decidido de antemano. "La lectura del presentepara que sea útil a la acción debe inscribirse, por tanto, en un horizonte lo más amplio posible y no debe dudar en cuestionar las razones de vivir y esperar" (Ladrière, 1977, p.19).

Ser humano - decimos con Ghelen, (1980, p.35) - es quien toma decisiones, forma una opinión, da su dictamen, toma partido por al go; es quien interviene en las cosas y al hacerlo también toma posición con respecto a sí mismo configurándose en lo que va siendo. En palabras de Kant "el ser humano tiene que producir todo por sí mismo" (1784). Ha de transformar él mismo las limitaciones de su existencia en oportunidades de prolongación de su vida y esto lo realiza a través de la acción. Sus actos son productivos para superar sus carencias y son sus propias elecciones para pilotear la vida. Haciendo mundo se hace a sí mismo y en ese hacerse configura el mundo. Ahí radica la fuerza de la cultura.

La acción humana, don de creación, es configuradora de cultura. Y la cultura no es más que el conjunto de formas sobre las que se apoya, sobrepasándolas necesariamente en el replanteamiento creador que está llamada a hacer. "En y por su cultura el individuo entra en la dimensión propiamente humana de su vida, se eleva por encima y más allá del animal que hay en él" (Ladrière, 1977, p.193). Al actuar, el ser humano crea, construye mundos que no son otra cosa que la naturaleza transformada en vida. La cultura es la naturaleza humana elaborada por los mismos seres humanos, la única en que podemos vivir. Es, diríamos, nuestra 'naturaleza' porque no hay posibilidad de existencia humana en una naturaleza no transformada. El mundo cultural es el mundo humano.

\section{Comunicación: tarea eminentemente humana}

La comunicación, temática tan amplia como la de la cultura, también se ha visto reducida en su posibilidad de sentido cuando se la equipara con información, con transmisión lineal de 'contenidos' o con medios técnicos. Con frecuencia las decisiones en torno a la comunicación se quedan en influir y unificar, en ofrecer recetas mágicas para la realización de acciones exitosas. A veces su función enmascarada en la libertad de expresión, busca a toda costa que los otros - los receptores - se acomoden a lo generado por quienes pueden ser enunciadores. Diríamos que son muchas las ocasiones en que se considera que la comunicación tiene éxito solamente cuando el otro piensa y actúa como yo me lo he propuesto. También es cierto que los estudios de comunicación, másque la tarea de los comunicadores, han ido demostrando que en buen 
sentido la comunicación se enraiza en la condición propia de lo humano. Es constitutiva de la relación entre los seres humanos como configuradores de comunidades y culturas.

Cada vez es más nítido cómo los procesos de comunicación contribuyen a desarrollar formas de interrelación más participativas y por ende más comprometidas con su entorno, a dar mayor flexibilidad a la creación humana como base de su permanente transformación, y a facilitar la interacción social de manera responsable para conjugar diversos intereses según los contextos socioculturales, políticos y económicos en donde se realicen. Esta visión nos obliga a asumir la comunicación de manera integral, reconociendo cómo atraviesa las acciones humanas, marcando estilos propios, constituyendo identidades y culturas y posibilitando nuevos sentidos a la sociedad.

La comunicación como hecho humano social es algo que se da en la práctica y que es y ha sido objeto de estudio y reflexión. Si aún se pone en duda su estatuto de ciencia creo que es porque seguimos creyéndonosel cuento de la ciencia positiva. Eso, sin embargo, no nos exonera de pensar qué sería lo propio de la comunicación como campo de estudio, como área del saber si la comunicación toca al ser humano en toda su existencia, y si a través de ella construimos mundos y anudamos comunidades. Parecería que todo y nada. Si bien es cierto que hace al gunas décadas la comunicación volvía sus ojos a las ciencias sociales, parece que hoy se ha dado la vuelta para dar luces y enriquecer el trabajo de lo humano en todos sus órdenes. Se volvió 'tutelar, punto de ruptura de las disciplinas', en términos de Armando Silva (1997).

En esta perspectiva me atrevo a distinguir tres caminos de estudio: el que nutre la comunicación, el que recoge de las ciencias sociales, las puras y aún de las áreas técnicas, elementos que le permiten perfilar mejor su campo de acción; otro, el que parte desde la comunicación para desde ahí descubrir las implicaciones en todos los órdenes de lo humano: en lo político, lo económico, lo científico, lo religioso, y claro está, en lo propiamente cultural. Y, en la mitad, como el mensaje mismo, el fenómeno de la comunicación, que jamás es punto fijo; es más un vacío, un sitio por llenar, un ámbito que posibilita las innumerables relaciones humanas, mucho más cercana de la contemplación estética que de la definición científica.

Comprender la comunicación, entonces, requiere ciertas precisiones, no a la manera de los objetos fijos que pretenden las ciencias positivas, y además requiere unas aptitudes muy especiales donde el rigor no está dado por las estadísticas ni las mediciones, sino, en términos de Peirce (Restrepo, 1993), por abducción, "il lumenaturale, ese poder interior que jalona la mente hacia la verdad", esa luz que nos permite ver el sentido precisamente en los vacíos, lo visible en lo invisible, lo posible en lo imposible.

La comunicación es siempre un terreno movedizo, imposible de asir directamente. Aún así, me arriesgo a proponer tres ámbitos propios de todo fenómeno de comunicaci- 


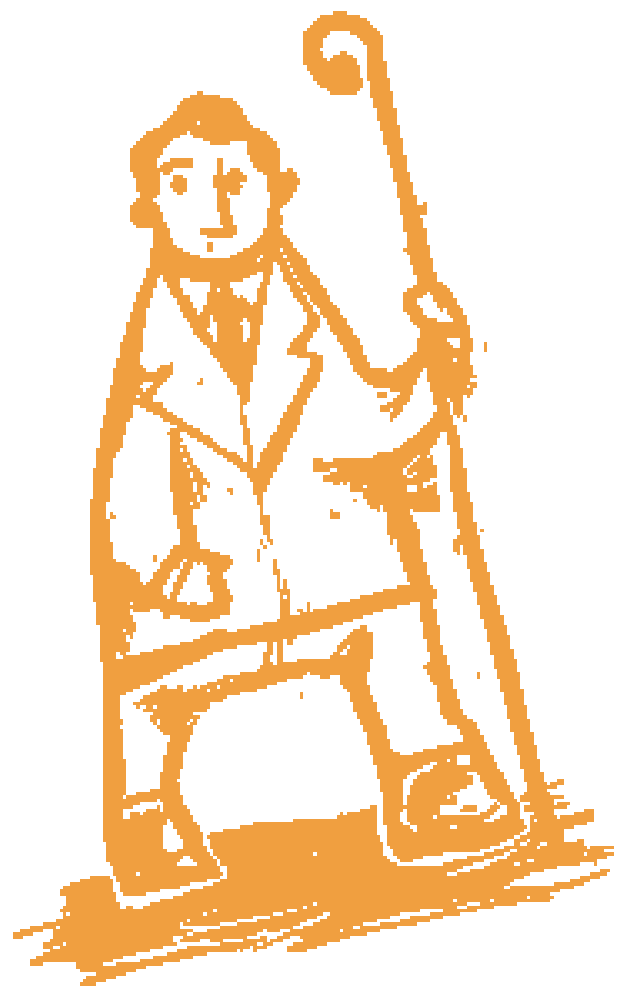

ón que se condensan en el mensaje y que si bien pueden distinguirse metodológicamente en aras de su análisis, son inseparables en la comunicación como fenómeno:

- El de la producción, esto es, el momento de creación, de construcción, de expresión humana en la que se seleccionan y combinan signos generando discursosy otros productos de comunicación;

- El de la TRANSMISIÓN ya sea distribución, circulación, proyección en la que se hacen presentes diversos recorridos y trayectos;

- Y el de la RECEPCIÓn, entendida como apropiación, lectura, interpretación, en últimas, como comprensión de sentidos posibles que de nuevo se plasman en otros modos de expresión: estamos ante nuevas poéticas y estéticas¹.

Pienso que la comunicación es uno de los campos de la actividad humana donde mejor se patentizan las características que la posmodernidad pone en evidencia. Y no me refiero a que este debate cruza por las transformaciones ocasionadas por los medios de comunicación que, como lo reconoció Walter Benjamin (1970) desde el siglo pasado, su papel ha sido más de informadores que de posibilitadores de relatos. Este aspecto, claro está, es ya muy diciente. Q uisiera referirme, más bien, a la comunicación en el sentido arriba expuesto. A sabiendas de perder los matices, puedo recoger con Lyotard (1986), Vattimo (1990) y otros pensadores de la posmodernidad que ésta se caracteriza porque los metarrelatos perdieron su legitimidad, ya no se aceptan perspectivasúnicas, y la historia no se asume como un proceso lineal y unitario. Podemos

1 He utilizado estos términos intencionalmente buscando resemantizarlos, volviendo a su origen, dándoles todo el sentido que se merecen: 'producción' como 'poiesis'; 'transmisión' como 'emitir más allá de...' y 'recepción' entendido como acto, como 'estar en apertura para...' 
decir con el gran escritor mexicano, Carlos Fuentes (1993), que hemos pasado de los metarrelatos a los multirrelatos que encuentran un campo propicio en la comunicación. ¿No es precisamente en la comunicación donde mejor se manifiesta la multiplicidad, la diversidad, las enormes diferencias entre los hombres y sus formas de pensar y de hacer? ¿No es la comunicación un modelo ejemplar de movimiento, de transformación, de opción por lo indefinido, por lo que está en permanente construcción? ¿No es en la comunicación en donde se pueden reconocer otras lógicas, otros órdenes que atraviesan la linealidad? ¿No es la comunicación, por gramática y por sentido, siempre femenina, entendida como esas formas de ser y de hacer no exclusivas de las mujeres que nos colocan ante lo sensible, lo difuso, lo posible?El campo de estudio de la comunicación me parece hoy privilegiado para la comprensión de nuestra existencia reflejada en nuestras manifestaciones culturales.

No hay duda de que la comunicación hoy es un punto de amalgama de las actividades del hombre. No importa por dónde se le mira, algo se le puede decir a la los procesos de comunicación y algo de esos procesos está implícito en toda actividad cultural. Con esto, no quiero salirme por la tangente, sino poner en evidencia la complejidad del tema. Estamos, de nuevo, ante la pregunta por el hombre y aunque me califiquen de extremista, diría yo, que la comunicación se ha configurado hoy en una nueva filosofía de lo humano en todas sus dimensiones.

\section{Profesando la comunicación}

¿Cómo entender la comunicación como profesión?En los términos descritos todos somos comunicadores, entonces, ¿qué papel le corresponde a un comunicador profesional? La comunicación se convierte en profesión, como ha ocurrido con otras actividades humanas, cuando esa actividad deja de ser de dominio familiar y se vuelve pública, cuando los procesos se vuelven más complejos, más técnicos y tienen una cobertura que en el caso específico de la comunicación hoy alcanza al planeta entero.

La complejidad en los procesos de producción y transmisión delimita, regula y altera la actividad originaria de la comunicación humana. Es enorme la responsabilidad de quienes les corresponde encargarse de procesos de producción y de transmisión de mensajes-posibles para ser descifrados y comprendidos por muchas personas, podríamos decir, abiertosa la inter pretación de toda la humanidad. Creo que aquí se hace necesaria la intervención de juiciosos procesos de formación y de reflexión que permitan a quienes desean pro-fesar2 la comunicación, reconocer las implicaciones de lo

2 Profesar en su sentido originario significa 'dar fe de algo'. El Diccionario de la Real Academia Española lo define como "Ejercer una ciencia, arte, oficio, etc.; Ejercer una cosa con inclinación voluntaria y continuación en ella; confesar. PROFESAR un principio, una doctrina, una religión". 
que hacen y dar cuenta a cabalidad de ello porque comprenden el mundo en el que viven y están dispuestos a inaugurar otros nuevos.

Temáticas muy propias de nuestro momento y sus particulares los modos de asumirse en nuestro continente requieren especial atención del profesional de la comunicación. La revalorización de la cultura llamada de 'masas', hoy denominada globalización y su contrapuesta, la 'mundialización' entendida como apropiación de lo común desde las particularidades y su relación con visiones económicas y políticas; la revisión de los medios, su génesis y desarrollo junto con las implicaciones de las nuevas tecnologías en la transformación de tiempos y espacios, de formas de mirar, de conocer y de vivir; el análisis de otras modalidades de expresión y recepción que nos conducen a formas-otras de cultura; la comprensión de imaginarios a través de sus expresiones simbólicas; la preocupación por lo urbano, la juventud, lo femenino-masculino como categorías de construcción simbólica de nuestros espacios y tiempos vitales, la cercanía con la narrativa como camino de construcción de identidades; las particularidades de las formas visuales y sus mezclas con sonido y palabra; las dimensiones poéticas y estéticas de los productos y actividades de la comunicación... todas estas temáticas han de estar presentes en la reflexión permanente de quienes profesan la comunicación para reconocer sus implicaciones en la vida de las comunidades, para ir desarrollando, formando criterios que permitan la toma de decisiones autónomas y responsables frente a su ejercicio profesional, no solo para hacer comunicación sino para comprender los procesos que otros generan y para reconocer las consecuencias de los que ellos mismos desatan.

El comunicador profesional, entonces, no se limitaría a crear productos de comunicación; sería, más bien, quien gesta comunicación con otros. Diría que se trata de permitir, de abrir mil y una posibilidades para que otros puedan generar procesos comunicativos. Es quien 'escucha', 'interpreta' mundos, abre caminos para la comunicación. Podemos pensarlo más como interprete, como seleccionador y combinador de posibilidades para generar con otros procesos de comunicación, trascendiendo la información. Otra cosa es que muchas empresas de comunicación no logren aceptar esta dimensión que desplaza los procesos meramente informacionales y efectivistas por otros que, haciéndole justicia a la comunicación humana, confrontan versiones, ponen de presente nuevas posibilidades, muestran mundos y construyen cultura.

En consecuencia, la comunicación como profesión cobija multiplicidad de campos. Si bien es cierto que la sociedad ha legitimado algunos, como el periodismo de manera privilegiada y otros como la publicidad, la producción audiovisual, la comunicación de las organizaciones, entre otros, el espectro cada día se abre más. Es frecuente encontrar la relación explícita de la comunicación con la educación, la salud, la administración, el desarrollo económico, la ecología, la política, la religión, las artes, la técnica por sólo mencionar al gunos campos. Basta con volver sobre la comunicación como constitutiva de lo humano en comunidad para descubrir que cualquier actividad hu- 


\section{mana está cruzada por ella; no es que todo sea comunicación, sino que ésta es condi- ción necesaria del desarrollo humano.}

\section{Bibliografía}

ARENDT, Hannah. La condición humana (1958). Barcelona: Paidós, 1996.

BENJ AMIN, Walter. El narrador en sobre el programa de la filosofía futura y otros ensayos. Caracasa: Monre Avila, 1970.

CASTORIADIS, Cornelius. Los dominios del hombre: las encrucijadas del laberinto (1975). Barcelona: Gedisa, 1988.

FUENTES, Carlos. Valiente mundo nuevo. México: FCE, 1993.

GHELEN, Arnold. El hombre (1974). Salamanca: Sígueme, 1980.

KANT, Emmanuel. Ideas para una historia universal. 1784.

LADRIĖRE, J ean. El reto a la racionalidad (1977). Salamanca: Sígueme-UNESCO, 1978.

LYOTARD, J ean-François. La condición posmoderna. Madrid: Cátedra, 1986.

RESTREPO, Mariluz. Ser signo interpretante: la filosofía de la representación de Charles Sanders Santiago Peirce. Bogotá: Significantes de Papel, 1993.

RICOEUR, Paul. Finitud y culpabilidad (1960). Madrid: Taurus, 1982.

SILVA, Armando. De los lenguajes a las estéticas en proyectar la comunicación. Bogotá: Tercer Mundo Editores-Universidad Nacional de Colombia, 1997.

VATTIMO, Gianni. Posmodernidad, una sociedad transparente en En torno a la posmodernidad. Barcelona: Anthropos, 1990.
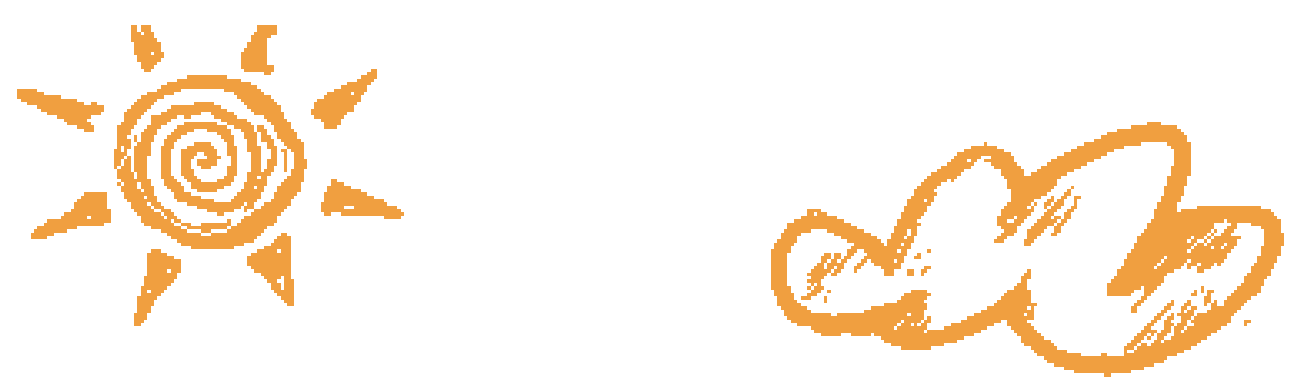